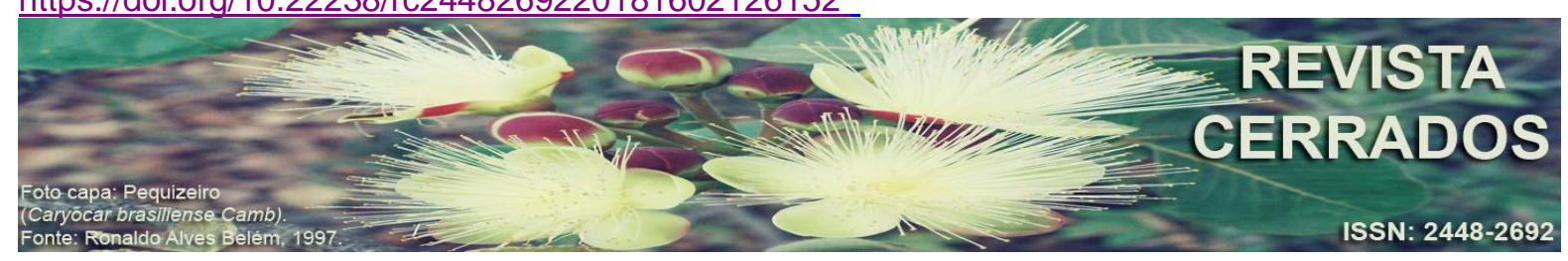

\title{
CIDADE HISTÓRICA TURÍSTICA, GLOBALIZAÇÃO E IDENTIDADES: conflitos e rearranjos na Cidade de Goiás (GO) observados na alimentação
}

\section{TOURIST HISTORICAL CITY, GLOBALIZATION AND IDENTITIES: conflicts and rearrangements in the City of Goiás (GO) observed in food}

\author{
CIUDAD HISTÓRICA TURÍSTICA, GLOBALIZACIÓN E \\ IDENTIDADES: conflictos y rearranjos en la Ciudad de Goiás (GO) \\ observados en la alimentación
}

\author{
Caio César Alencar de Sena \\ Universidade Federal de Goiás - UFG \\ E-mail: <caiosenageo@gmail.com>.
}

\begin{abstract}
RESUMO
Este artigo discute a problemática da construção de identidades no território inserido nas redes globais. Considera-se enquanto recorte espacial a cidade de Goiás, dentro da Região Turística do Ouro em Goiás. O objetivo central é verificar de que forma traços da alimentação podem compor a identidade dos territórios e dos sujeitos. Busca-se ainda compreender os conflitos entre o tradicional e o moderno em um território tombado como patrimônio, que ao longo dos últimos anos passaram a ser atravessadas por símbolos e referências culturais forçadas pela intensificação da globalização. A metodologia desta pesquisa contou com revisão bibliográfica sobre a temática, dois trabalhos de campo, entrevistas semiestruturadas com moradores e turistas na Cidade de Goiás, espacialização de dados em mapas e registros fotográficos dos territórios analisados. Os resultados apontam que as construções identitárias são sempre plurais e construídas historicamente. Muitas vezes, as identidades sofrem reducionismos ou generalização em nome de uma possível representatividade de um território, um povo ou uma nação. Notou-se ainda que mesmo quando pouco percebidas no plano político e cultural, as identidades são utilizadas estrategicamente para controlar os territórios e construir estereótipos acerca das pessoas, dos lugares e das coisas.
\end{abstract}

Palavras-chave: Identidade. Território. Alimentação e Turismo. Região Turística do Ouro. Cristais. 
SENA, C. C. A.

Cidade histórica turística, globalização e identidades: conflitos e rearranjos na Cidade de Goiás (GO) observados na alimentação

\begin{abstract}
This article discusses the problem of the construction of identities in the territory inserted in the global networks. The central objective is to verify how traces of food can reveal and build the identity of territories. The specific objectives are to understand the conflicts between the traditional and the modern in a heritage land, which over the last years have been crossed by symbols and cultural references forced by the intensification of globalization. The methodology of this research include a bibliographical review on the subject, two field studies, semi-structured interviews with residents and tourists in Cidade de Goiás, spatialisation of data on maps and photographic records of the analyzed territories. The results point out that identity constructions are always plural and built. Often identities are reduced or generalized in the name of a possible representation of a territory, a people or a nation. It was also noted that even when little perceived in the political and cultural spheres, identities are used strategically to control territories and construct stereotypes about people, places and things.
\end{abstract}

Keywords: Identity. Territory. Food and Tourism. Gold Tourist Region. Crystals.

\title{
RESUMEN
}

Este artículo discute la problemática de la construcción de identidades en el territorio insertado en las redes globales. Se considera como recorte espacial la Ciudad de Goiás, dentro de la Región Turística del Oro en Goiás. El objetivo central es verificar de qué forma rasgos de la alimentación pueden componer la identidad de los territorios y de los sujetos. Los objetivos específicos son comprender los conflictos entre lo tradicional y lo moderno en un territorio tumbado como patrimonio, que a lo largo de los últimos años pasaron a ser atravesados por símbolos y referencias culturales forzadas por la intensificación de la globalización. La metodología de esta investigación contó con revisión bibliográfica sobre la temática, dos trabajos de campo, entrevistas semiestructuradas con moradores y turistas en la Ciudad de Goiás, espacialización de datos en mapas y registros fotográficos de los territorios analizados. Los resultados apuntan que las construcciones identitarias son siempre plurales y construidas históricamente. Muchas veces, las identidades sufren reduccionismos o generalización en nombre de una posible representatividad de un territorio, un pueblo o una nación. Se notó que incluso cuando poco percibidas en el plano político y cultural, las identidades son utilizadas estratégicamente para controlar los territorios y construir estereotipos acerca de las personas, de los lugares y de las cosas.

Palabras clave: Identidad. Territorio. Alimentación y Turismo. Región Turística del Oro. Cristales.

\section{INTRODUÇÃO: É POSSİVEL ESCAPAR DA GLOBALIZAÇÃO?}

Neste artigo é realizada uma reflexão acerca das identidades em um jogo de disputas a partir do território de uma cidade turística e histórica tombada como patrimônio da 
SENA, C. C. A.

Cidade histórica turística, globalização e identidades: conflitos e rearranjos na Cidade de Goiás (GO) observados na alimentação

humanidade. Seleciona-se para tanto a cidade de Goiás, localizada na Região Turística do Ouro em Goiás. Essa escolha deu-se por conta das características culturais, paisagísticas e arquitetônicas de tal cidade, que serão melhor exemplificadas ao longo do estudo. Adianta-se que um dos motivos predominantes dessa escolha é que a cidade de Goiás tem uma tendência a ser menos aberta ao turismo de massa e a algumas imposições de ritmos acelerados ditados normalmente por cidades maiores ou metrópoles.

Parte-se do pressuposto que cada cidade pode ter várias histórias e também várias identidades. As histórias que se afirmam como hegemonias ou "mais importantes" são assim compreendidas normalmente por conta de estruturas de poder e, olhando mais de perto, por conta de sujeitos ou gestores que se utilizam de instituições para tentar impor "tradições" ou modos de vida em determinado contexto no tempo e no espaço.

A possibilidade de emergência de uma ou outra história como predominante já foram observadas por Foucault $(1984,1996)$ quando o mesmo estudou as relações de poder em diversas dimensões sociais, não apenas na relação vertical entre Estado e sociedade, mas também de forma horizontal, nas mais variadas formas de vivência cotidiana. A mesma discussão pode ser estendida quando se pensam nas identidades predominantes que se projetam a partir de sujeitos, lugares ou paisagens. Essas também podem ser construídas ou desconstruídas, a partir de um jogo cultural complexo e que, também, pode ser permeado por relações de poder.

A discussão aqui proposta é realizada com foco nas interferências que até mesmo uma dita cidade histórica possui por conta do crescente diálogo com elementos da globalização e da mundialização. Almeja-se compreender melhor como esse relacionamento entre o local e o global pode impactar, inclusive, essas cidades resguardadas como "tradicionais" e que possuem parte da arquitetura tombadas como patrimônio histórico - ou seja, quase nenhum território escapa das interferências globais em parcelas do local.

Discute-se, a partir da observação dos hábitos alimentares e dos estabelecimentos de alimentação (como por exemplo restaurantes, quiosques, pequenas vendas, dentre outros) as diferentes interferências que novos moradores ou turistas e seus também "novos" hábitos alimentares podem promover nos territórios de cidades patrimônio. A cidade escolhida para a discussão já foi capital do estado de Goiás e atualmente, parte de suas identidades tem se tornado produto turístico, sobretudo a fachada de alguns prédios no centro da cidade. Notou- 
SENA, C. C. A.

Cidade histórica turística, globalização e identidades: conflitos e rearranjos na Cidade de Goiás (GO) observados na alimentação

se em trabalho de campo que inclusive algumas memórias vinculadas ao período do ouro destacadas por Palacín (1994) também foram transformadas em museus ou espaços mais simples para visitação, que atrai turistas de diferentes idades, sobretudo estudantes e professores (as) de escolas públicas.

Dentre os agentes que influenciaram essas mudanças de identidades ou, pelo menos uma necessidade de diálogo entre elementos "novos" e "velhos" na cidade de Goiás, destacam-se: a constante chegada e partida de turistas, os (as) estudantes universitários (as) matriculados em cursos das instituições Federal e Estadual (novas turmas fazem matriculas anualmente, assim como outras turmas formam e se vão). Além desses sujeitos em trânsito, pode-se dizer que as mídias (televisão, celular, computador, rádio, dentre outros) também carregam simbolismos que fazem com que a cidade histórica precise dialogar constantemente com o que está para fora dos seus limites municipais.

Dentre os diversos elementos do mundo moderno, optou-se por observar os hábitos alimentares de turistas e estudantes, bem como as mudanças recentes ocorridas em estabelecimentos de alimentação da cidade, que buscam atender a algumas demandas das pessoas que chegam. Cabe ressaltar que esse "atendimento de demanda" nem sempre é prioridade para os moradores mais antigos da cidade, por esse motivo, existe também relações conflituosas entre o que turistas, estudantes e a população local planejam para a cidade: seja para a manutenção ou ruptura de padrões sociais ditos como tradicionais.

Destaca-se que o objetivo central do artigo é verificar a importância da alimentação na constituição das identidades territoriais na cidade de Goiás. Enquanto que o objetivo específico, recairá sobre a compreensão dos conflitos entre o tradicional e o moderno em um território tombado como patrimônio, que ao longo dos últimos anos passaram a ser atravessadas por símbolos e referências culturais forçadas pela intensificação dos processos vinculados a globalização. Notou-se a necessidade dessa melhor compreensão pois a globalização de cidades patrimônio pode colocar em cheque a proposta de patrimonialização ou até mesmo constituir novas configurações para as identidades locais.

Para ponderar brevemente sobre esses dois conceitos: globalização e mundialização, dialoga-se com autores como Ortiz (1994), que analisou o termo globalização como algo esquematizado para se referir aos processos econômico-tecnológicos e a mundialização para os processos de ordem cultural. Em outra via, Amin (1999) afirma que a 
SENA, C. C. A.

Cidade histórica turística, globalização e identidades: conflitos e rearranjos na Cidade de Goiás (GO) observados na alimentação

globalização da sociedade e da economia gera a mundialização do espaço geográfico, carregando-o de novo significado, já Haesbaert (1998), aponta as estratégias territoriais dessas fragmentações pautadas em uma lógica de "fragmentar para melhor globalizar". Apesar de entender essa diferenciação, optou-se por utilizar nesta pesquisa o termo globalização para tratar dos processos analisados.

Os crescentes envolvimentos dos territórios com as redes técnicas (transportes, comunicação, dentre outros) têm criado novos desafios para o ordenamento territorial e ao planejamento das cidades, principalmente quando se pretende dar luz às particularidades ou elementos das identidades dos lugares vinculadas às tradições. Torna-se também um desafio cada vez maior indicar de forma responsável partes ou elementos de uma cidade que deveriam ser compreendidos e aceitos como patrimônios a serem tombados, pois é cada vez mais perceptível nos territórios e nas paisagens a sequência de ondas e interferência do global no local.

Essas reflexões iniciais nos levam até questionamos como: o que é de fato uma cultura local? É possível estabelecer uma origem para as identidades ou os hábitos de determinados povos? O que deve ou não ser entendido como prioritário e que precisa ser resguardado a populações futuras?

Ao observar os hábitos alimentares, percebe-se que na cidade de Goiás, as novas demandas trazidas por estudantes têm ressignificado as paisagens, as dinâmicas de funcionamento das ruas da cidade histórica e talvez em um futuro próximo pode-se falar até em alterações nas identidades locais. Notou-se ainda que a população local tem demonstrado certa dificuldade em conviver simultaneamente com os novos elementos trazidos até a cidade. Ora existe uma força para manter tradições, ora a necessidade de incorporar elementos algumas vezes vistos como "estranhos" do mundo externo à cidade histórica 1 .

Os impactos externos nas culturas locais é algo complexo e que pode ser evidenciado em muitos elementos espaciais de nosso tempo. Neste artigo apresenta-se as alterações territoriais e de paisagem levando em consideração aspectos da alimentação. As reflexões são fruto da leitura compartilhada de textos sobre identidades, territórios e

\footnotetext{
${ }^{1}$ Este artigo não tem pretensões de discutir o conceito de cidade histórica na Geografia. Por isso, quando o termo aparece, a referência é a cidade de Goiás, primeira capital do estado que possui o conjunto arquitetônico, paisagístico e urbanístico de partes do centro tombados pelo Iphan em 1978 e inscrito na Lista do Patrimônio Mundial da UNESCO em 16 de dezembro de 2001.
} 
SENA, C. C. A.

Cidade histórica turística, globalização e identidades: conflitos e rearranjos na Cidade de Goiás (GO) observados na alimentação

territorialidades de uma disciplina ministrada para estudantes de Pós-Graduação em Geografia da Universidade Federal de Goiás em 2016, que resultou em novos direcionamentos para trabalhos de campo para uma dissertação de um Mestrado em andamento.

\section{METODOLOGIAS E CAMINHOS DA PESQUISA}

O caminho para a discussão das questões relacionadas às identidades, ao território e à cultura a partir das mudanças de hábitos alimentares na cidade histórica de Goiás, se inicia com as considerações acerca do território e redes, passa pela reflexão sobre o problemático conceito de identidades na contemporaneidade e, por fim, apresenta-se a caracterização de alguns estabelecimentos alimentícios frequentados por turistas e estudantes, sondando os impactos dos mesmos nas culturais, dinâmicas territoriais e paisagens locais.

Para verificar como se dão as construções das identidades da cidade de Goiás, sobretudo às vinculadas de alguma forma à alimentação, foram realizados dois trabalhos de campo na cidade de Goiás, o primeiro em novembro de 2015 e o segundo em maio de 2016, durante o Circuito Gastronômico de Goiás, onde foram realizadas sondagens e registros fotográficos de estabelecimentos e dos espaços dedicados aos alimentos na cidade histórica selecionada, realização de entrevistas semiestruturadas e diálogos informais com turistas, estudantes e moradores mais antigos na cidade.

Ao todo foram realizadas dez entrevistas com pessoas de diferentes faixas etárias e grupos sociais, com a finalidade de registrar mais elementos qualitativos do que quantitativos nas entrevistas, pois o artigo contemplou ainda pesquisas em bases de dados secundários para o levantamento de informações quantitativas necessárias à reflexão aqui posta. Entendeu-se que os dados qualitativos deveriam ser priorizados nas entrevistas porque o que estava em discussão eram as identidades vinculada aos territórios, dessa forma a simples observação dos hábitos alimentares ou dos estabelecimentos não podiam dar conta dos objetivos que selecionamos. Quanto a revisão bibliográfica, foram compilados e analisados os conceitos de identidade e impactos da globalização com Bauman (2006), Appadurai (1994), Canclini (2006) e Claval (1999, 2010).

Enquanto que Almeida (2009), Saquet (2005) e Nora (1993) foram importantes para as discussões sobre patrimônio, território, poder e identidade. Além das revisões 
SENA, C. C. A.

Cidade histórica turística, globalização e identidades: conflitos e rearranjos na Cidade de Goiás (GO) observados na alimentação

bibliográfica, salienta-se ainda que os trabalhos de campo revelaram especificidades da cidade de Goiás que contribuíram com os objetivos geral e específicos citados, muitas dessas contribuições estão apresentadas junto a caracterização dos estabelecimentos visitados, bem como dos cardápios e produtos comercializados, que demonstraram os diálogos entre o local e o global com bastante evidência na cidade histórica analisada.

\section{TERRITÓRIO, IDENTIDADE E REDES DA GLOBALIZAÇÃO}

A interpretação dos diversos territórios caminha com as noções de poder vinculado às tentativas de controle de determinados espaços. Muitos autores fizeram pesquisas que demonstraram que as apropriações territoriais possuem tanto a dimensão técnica e material de controle, quanto o caráter simbólico ou cultural. O geógrafo Haesbaert (1997, p.39) identifica três eixos e abordagens conceituais do território: a) jurídico-política com destaque ao caráter estatal, b) culturalista que "prioriza sua dimensão simbólica e mais subjetiva" e c) a vertente econômica que evidencia a "des-territorialização em sua perspectiva material". Usualmente, pesquisas que encontram um paralelo possível entre identidade e território, parece partirem de uma inquietação: o que difere um território de outro? Compreende-se neste artigo a dimensão econômica e de poder junto aos territórios, porém, é colocado em discussão o poder dos hábitos alimentares em promover novas territorialidades por meio do surgimento de novos estabelecimentos alimentícios.

Entre as diversas formas de responder ou de refletir o que existe de especificidade entre os territórios, pode-se considerar Santos (1999), quando afirma que identidade é o sentimento de pertencer àquilo que nos pertence. Segundo esse autor, as identidades estão relacionadas com a produção e atividade exercidas pelo indivíduo. Ao considerar as ideias propostas por Cruz (2007), ampliando a noção sobre como as identidades são construídas, compreende-se que "toda identidade é uma construção histórica e relacional dos significados sociais e culturais que norteiam o processo de distinção e identificação de um indivíduo ou de um grupo" (CRUZ, 2007, p. 17).

A partir desse entendimento, outros aspectos tomam força no processo de identificar territórios, com destaque ao fato da identidade ser uma construção histórica e relacional. Ainda de acordo com Cruz (2007), é necessário atentar-se ao fato de que a 
SENA, C. C. A.

Cidade histórica turística, globalização e identidades: conflitos e rearranjos na Cidade de Goiás (GO) observados na alimentação

identidade está sujeita a manipulação dos indivíduos ou dos grupos sociais. Ou seja, não existe direcionamento neutro para o processo de constituição identitária. No exemplo estudado entende-se que tanto a população local, turistas, estudantes ou as mídias globais que chegam até as cidades históricas estão envolvidas por intencionalidades. Como salientam Hobsbawm e Ranger (1984) até mesmo as tradições podem ser inventadas.

Considera-se, portanto, que as identidades não existem por si só, independente dos atores sociais. Alguns pesquisadores conseguiram aliar o conceito de identidades ao de territorialidade pondo foco nas lógicas que permeiam esses dois conceitos. Gomes (2005, p.38) afirmou que territorialidade são "as estratégias, seja no arranjo da ordem espacial ou no controle do seu uso". Já Saquet (2005) pontuou que a territorialidade está vinculada às ações ou tentativas de dominação, ou seja, tentativas de indivíduos ou grupos sociais para influenciar, controlar pessoas, fenômenos naturais, sociais, econômicos, culturais e políticos as quais delimitam e efetivam o controle sobre uma determinada área territorial.

Diante do breve exposto torna-se possível relacionar estratégias de dominação e controle por meio de elementos culturais, por exemplo. Esse aspecto interessa substancialmente a análise aqui proposta, uma vez que a alimentação e suas práticas são entendidas como um traço da cultura dos territórios, que por sua vez são construídas e vividas a partir de um emaranhado de relações. Almeida (2009) situa o território como um amálgama de signos e significados conforme a conjuntura social e cultural em que tais signos estão inseridos. Considera-se ainda que as alterações técnicas no mundo moderno modificaram também a construção e as formas das cidades, o que poderá repercutir, com o passar do tempo e com a chegada dessas instalações e redes, no modo de vida das pessoas, como observou Santos (2009).

As cidades que possuem tombamentos e elementos entendidos como patrimônio da humanidade, quando passam a receber um número elevado de turistas, tendem a necessitar de maior rede de restaurantes, comidas de rua e afins. Nesse processo, existe tanto um necessário incremento das infraestruturas físicas para atender o maior número de pessoas essas novas construções alteram as paisagens e também elementos da cultural local, para conseguir dialogar de alguma forma com os hábitos alimentares advindos de turistas e estudantes. Sobre esse processo de alteração de fluxos simbólicos e culturais, Silva (1996) aponta que continuidades e mudanças podem ser observadas nas dinâmicas culturais. 
SENA, C. C. A.

Cidade histórica turística, globalização e identidades: conflitos e rearranjos na Cidade de Goiás (GO) observados na alimentação

Enquanto que Castells (1999, p. 497) afirma que as "redes constituem a nova morfologia social de nossas sociedades, e a difusão da lógica de redes modifica de forma substancial a operação e os resultados dos processos produtivos e de experiência, poder e cultura". Ou seja, existe uma notória alteração do meio físico que também reverbera na relação poder - cultura, instâncias as vezes abafadas por serem "invisíveis".

\section{CONTROVÉRSIAS TERRITORIAIS E CULTURAIS NAS REFLEXÕES SOBRE AS IDENTIDADES GOIANAS}

Ao se pensar no território goiano conectado por redes, tanto os materiais quanto as imateriais, parecem existir cidades com maiores ou menores possibilidades de expressar, revelar ou construir suas identidades. Porém, ao se aproximar dos territórios e das cidades, percebe-se que nem sempre uma hierarquia automática ou os aspectos culturais tais como o que se seleciona para compreender as identidades dos lugares são possíveis de serem captados de forma simples.

Goiânia enquanto capital de Goiás se apresenta como centralidade para uma série de serviços, produtos, infraestruturas e afins, até por conta das hierarquias urbanas. Quando se considera os estudos das Regiões de Influência das Cidades (REGIC), elaborado pelo Instituto Brasileiro de Geografia e Estatística (IBGE) em 2007, Goiânia é uma cidade que polariza e influencia diversas outras cidades na região Centro-Oeste e até fora dela. Porém, a influência das cidades não diz respeito apenas ao caráter técnico ou material que as redes físicas proporcionam. O estudo de identidades, por exemplo, requer um olhar menos automático para a questão das hierarquias e das centralidades. Nem sempre as localidades mais metropolitanas ou com maior número de população e infraestruturas representam identidades singulares ou "tradicionais". A construção de identidade, apesar de dialogar com as redes do território, possui lógicas específicas que também perpassam os limites técnicos da gestão territorial.

Ao tentar responder o que é ser goiano, o escritor Bariani Ortêncio elaborou três publicações mais robustas: “A Cozinha Goiana Estudo e receituário” (1967), "Dicionário do Brasil Central" (1983) e "Medicina Popular do Centro-Oeste" (1990). Em todos esses livros, a identidade goiana precisou extrapolar a capital para ser melhor compreendida. Isso significa que os estudos sobre identidades convidam os pesquisadores a observar com atenção 
SENA, C. C. A.

Cidade histórica turística, globalização e identidades: conflitos e rearranjos na Cidade de Goiás (GO) observados na alimentação

localidades menos centralizadas. Pois a medida com que a cidade cresce e se globaliza, é comum o aumento na recepção de influências de outros territórios. Nesse processo, as tradições ou os padrões materiais e imateriais podem entrar em disputa com elementos da globalização vindos de diversas localidades e, dependendo da gestão cultural dos municípios e da recepção da população, itens fundamentais da cultura local podem ser pulverizados ou ressignificados com o passar do tempo.

Quando o Serviço Brasileiro de Apoio às Micro e Pequenas Empresas - Goiás (SEBRAE Goiás) publicou Elementos da Iconografia de Goiás (2015), buscou junto com uma equipe técnica explicar as identidades goianas a partir dos símbolos culturais do Estado. Por meio de uma pesquisa de símbolos do território goiano que durou dois anos, além dos ícones de Goiânia, foram incorporados no itinerário Alto Paraíso, Cavalcante, Cidade de Goiás, Corumbá, Pirenópolis, Serranópolis, Teresina, Trindade e ainda o Parque das Emas e Chapada dos Veadeiros, para então posteriormente elaborar uma cartilha com identificações do território de Goiás a partir dos seguintes recortes temáticos: arqueologia, arquitetura, arte religiosa, atrativos naturais, fauna, flora, folclore e cultura. A publicação em questão entende que todos esses aspectos podem compor, de alguma forma, as várias facetas, das várias identidades goianas.

Esses exemplos demonstram o paradoxo enfrentado por pesquisadores que se dedicam ao estudo de identidade. Ou seja: nem sempre uma maior amostragem de objetos ou população pode reunir mais elementos que expliquem uma identidade - o que também é comum em outros conceitos que tangenciam ou são encarados como subjetivos. É igualmente interessante notar que as identidades podem ser construídas a partir da linha tênue entre o que diferencia e o que se assemelha, ou, nas palavras de Azevedo (2007), no limite entre o estereótipo entre "nós" e o "outro".

A busca de se chegar a uma identidade única de determinada região, povo, cultura ou qualquer que seja o elemento, pode ser perigoso e se tornar apenas uma generalização. É importante considerar que existem limitações nas construções de identidade. Canclini (2001) alerta ao risco de gerar ideias violentas em relação ao outro, pois é complicado representar grupos heterogêneos com ideias ou concepções homogêneas. Para minimizar esse risco de equívoco, Canclini (2001) utiliza a noção de "reconhecimento", que se trata de um conceito 
SENA, C. C. A.

Cidade histórica turística, globalização e identidades: conflitos e rearranjos na Cidade de Goiás (GO) observados na alimentação

que integraria a alteridade e permitiria uma dialética entre os grupos a qual se pretende identificar, por se basear na reciprocidade.

Ao serem construídas, as identidades tendem a considerar às redes e disputas do território onde estão inseridas, conforme observou Haesbaert (2009). Portanto, ao se falar em identidades, ou mesmo nos conceitos expandidos tais como identidades territoriais deve se ter noção de que elas são constituídas por processos complexos e que no final não representam um todo homogêneo, mas sim um agrupamento parcialmente condizente com alguma coisa ou algum grupo. Dizer sobre, requer considerar a ideia de identificação, de reciprocidade, mas não que todos os elementos ou todos os povos se sentirão representados por uma única identidade. E nem por isso, tais identidades não podem ser utilizadas ou forçadas por veículos de comunicação, por instituições variadas ou pelo próprio Estado com objetivos específicos, tais como a projeção ou uso de identidades para a construção de um destino turístico.

Quando se apresentam referências como "terra do pequi", "duplas sertanejas", "belas cachoeiras", "povo acolhedor" "festivais de rock alternativo", "uai" dentre outros conjuntos de características para caracterizar Goiás, percebe-se reforços de imaginários ou a atribuição de identidades. Não significa, portanto, que essas expressões conseguem dizer da complexidade de um povo, de uma cidade ou mesmo todos os traços de uma culinária local. Significam somente ou simplesmente que, de forma alguma, tais elementos passaram a fazer parte da cultura ou que são elementos possíveis de serem utilizados quando se pretende identificar uma parcela do território. É preciso compreender que identificar não significa representar uma totalidade homogênea, pois as identidades podem se aproximar de estereótipos, capazes de seresm desconstruídos com a mesma velocidade em que são construídos.

\section{TERRITÓRIO E IDENTIDADE EM “CIDADES PATRIMÔNIO” APROPRIADAS PELO TURISMO}

A partir dos pressupostos apresentados, entende-se que para compreender as identidades é necessário considerar a contribuição de lugares dialógicos. Contudo, nem sempre as respostas mais significativas estão nas localidades mais influenciadas pela globalização. Assim, algumas questões vêm à tona: Quais seriam as vantagens de se estudar a 
SENA, C. C. A.

Cidade histórica turística, globalização e identidades: conflitos e rearranjos na Cidade de Goiás (GO) observados na alimentação

construção de identidade em uma região turística? A escolha da cidade de Goiás, na Região Turística do Ouro, baseou-se na argumentação de Claval (2010), quando o mesmo afirma que a cultura e as dinâmicas simbólicas são centralidades na diferenciação dos territórios e elementos importantes para a abordagem geográfica. Por isso é necessário o estudo dos elementos culturais de Goiás, ao definir como objetivo investigar como o território em questão se aproxima ou se diferencia dos demais territórios.

A Figura 1 apresenta a cidade de Goiás dentro da Região Turística do Ouro e Cristais, que é uma das dez regiões turísticas do estado, englobando os 49 destinos selecionados e regionalizados pela Goiás Turismo, em sintonia com as diretrizes do Ministério do Turismo (MTur). Na figura, observa-se a cidade de Goiás e Mossâmedes a oeste, separados dos demais municípios da mesma região à leste. Não é foco deste estudo questionar o tipo de regionalização proposto pela Goiás Turismo, mas sim avaliar a forma que as regiões turísticas podem servir à pesquisas sobre as identidades dos territórios.

Figura 1 - Localização do município de Goiás na Região Turística do Ouro e Cristais

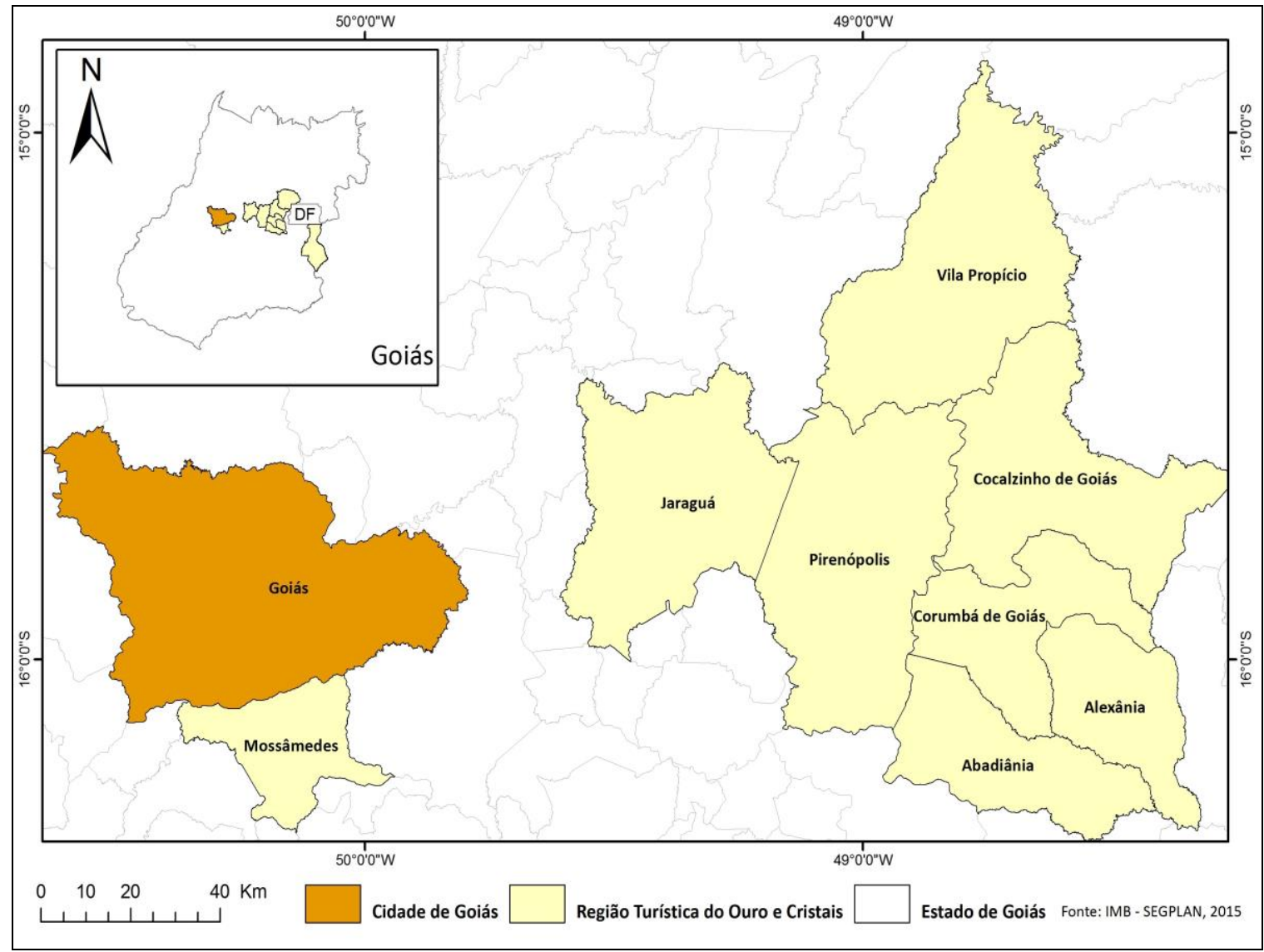

Fonte: IMB - SEGPLAN, 2015. Elaboração: O Autor (2016).

Revista Cerrados, Montes Claros/MG, v. 16, n. 2, p. 126-152, jul./dez.-2018. 
SENA, C. C. A.

Cidade histórica turística, globalização e identidades: conflitos e rearranjos na Cidade de Goiás (GO) observados na alimentação

O município de Goiás ganhou repercussão internacional quando elementos de sua identidade e cultura foram tombados como patrimônio da humanidade em 2001, com o aval da Organização das Nações Unidas para a Educação, Ciência e Cultura (Unesco). O reconhecimento do centro histórico da cidade como patrimônio encerrou uma mobilização política que começou em 1998, coordenada pelo Movimento Pró-Cidade de Goiás e que articulou os agentes da própria cidade com o Instituto do Patrimônio Histórico e Artístico Nacional (Iphan), além dos governos municipal e estadual.

Esse tipo de declaração, ou seja, a atribuição ou classificação de algumas cidades como "históricas", tende a agregar territorialidade à cidades específicas, utilizando do poder das instituições em consagrar símbolos nacionais que, segundo as mesmas, são merecedoras de perpetuação por serem "lugares da memória", ou como destaca Nora (1993, p. 18), cidades onde a estabilidade e a preservação de sua cultura favorecem "o relembrar e o reencontrar do pertencimento, princípio e segredo da identidade" que passa a ser uniformizada e imposta como ícones identitários nacional ou regional.

Uma das consequências desse tipo de reconhecimento enquanto patrimônio é a potencialização dos territórios tombados enquanto atrativos turísticos. Na Região Turística do Ouro, existem cidades que possuem elementos tombados internacionalmente, como o caso de Goiás com a UNESCO; outras são tombadas e reconhecidas nacionalmente pelo IPHAN: Pirenópolis, Jaraguá e Corumbá de Goiás e, novamente a própria Cidade de Goiás; e por fim as cidades tombadas pelo estado ou pelos municípios, como é o caso de Mossâmedes.

Além de impactar diretamente as cidades que passam a ser patrimônio, esse tipo de reconhecimento chama a atenção de turistas para cidades próximas ou vizinhas. A constância de visitantes aumenta o fluxo de pessoas em trânsito pela cidade, o que pode reverberar até mesmo na dinâmica da região, e isso tudo acontece mesmo quando a busca por “ser cidade patrimônio" não é desejo ou plano dos próprios moradores. Conforme observou Paes $(2015$, p. 45) “(...) a valorização do patrimônio cultural respondeu à produção de ideias, ideologias espaciais e teorias que, saídas das políticas públicas, vão representar os símbolos valorizados em cada período histórico".

Por esse motivo, muitas vezes a patrimonialização das cidades são frutos de arranjos políticos nem sempre amplamente discutidos com a população local. E, ao serem tombadas, a identidade dessas cidades são projetadas regional, nacional ou até 
SENA, C. C. A.

Cidade histórica turística, globalização e identidades: conflitos e rearranjos na Cidade de Goiás (GO) observados na alimentação

internacionalmente a partir de elementos culturais ligados ao conjunto arquitetônico ou, em outros casos, de elementos da cultura imaterial.

Nesse ajuste de interesses, a identidade passa a ser também elemento de poder. $\mathrm{O}$ autor Castells (1999), possui grande contribuição nas explicações de como os atributos culturais das identidades também adentram os jogos de poder dentro do território, para melhor exemplificação de sua crítica, o autor subdivide a identidade em três grupos: identidade legitimadora, identidade de resistência e identidade de projeto. Além dessa divisão, a respeito da problemática de construção das identidades, seria:

(...) o processo de construção de significado com base em um atributo cultural, ou ainda num conjunto de atributos culturais inter-relacionados, o (s) qual (is) prevalece (m) sobre outras fontes de significados. Para um determinado indivíduo, ou ainda para um ator coletivo, pode haver identidades múltiplas. No entanto, essa pluralidade é fonte de tensão e contradição tanto na auto-representação quanto na ação social. (CASTELLS 1999, p.22, grifo nosso)

Devido a essa tensão existente, pode-se fazer uma relação possível a partir do paralelo entre o que se tem ou se tinha de identidade no território antes das cidades serem reconhecidas como patrimônio e, do outro lado, o que passa a acontecer a partir do conflito da identidade local com a identidade dos visitantes vindos de outros territórios atraídos pelo turismo. Com isso, observa-se uma mistura fértil para a construção de identidades vinculadas ao mundo global.

É importante no estudo de identidade considerar o enfrentamento local-global, pois conforme afirmação de Hall (1997, p.13), a identidade não deve ser entendida como algo lapidado e acabado, mas sim algo em constante mutação: “dentro de nós há identidades contraditórias, empurrando em diferentes direções, de tal modo que nossas identificações estão sendo continuamente deslocadas", ou seja, o turista impacta diretamente a cultura e a identidade local ao transitar pelo território, da mesma maneira em que também é impactado.

Em algumas cidades, a exemplo da cidade de Goiás, parece haver receio de incorporar o turista dentro da gestão territorial ou ritmo de vida local. Existe inclusive, uma espécie de orgulho local em não fazer parte ou não trabalhar explicitamente para o turismo de massa. Quem visita essa cidade pode ter a sensação de que a população local oferece resistência às novas ideias ou modos de vida trazidos por visitantes. Exemplos disso podem ser revelados em pequenos diálogos ou no cotidiano, a partir de observações realizadas durante trabalho de campo em novembro de 2015, quando a proprietária de uma pousada, 55 
SENA, C. C. A.

Cidade histórica turística, globalização e identidades: conflitos e rearranjos na Cidade de Goiás (GO) observados na alimentação

anos, relevou: "então você não é daqui? Se veio querendo sossego tá no lugar certo. Aqui em Goiás não tem aquela bagunça de outras cidades turísticas, o povo que chega é que entra no nosso ritmo" (sic) ${ }^{2}$.

Outros turistas que visitaram a cidade se depararam com situações relatadas por eles como "fora do comum", decorrente dessa mesma característica de preservação do ritmo local. Um turista, encontrado no mesmo trabalho de campo, disse: "não entendo Goiás Velho ser cidade turística, vim pra cá em finais de semana de férias e encontrei tudo fechado: restaurantes, museus e lojas. Já hoje, também final de semana, tá tudo aberto, vai entender? Parece que o povo daqui atende no dia que quer" (sic) D.R.L, 25, empresário de Goiânia.

Por mais que esses estilos de vida possam causar estranhamentos em turistas, alguém querer ser atendido a qualquer momento, também pode surpreender a população local. Nas conversas com a comunidade, têm-se a impressão de que a cidade turística "patrimônio da humanidade" não se insere na realidade dos moradores.

Por mais que alguns demonstram se sentirem orgulhos desse título, outros desconhecem ou não se importam com as projeções que o turismo pode ter. Em outro diálogo, uma funcionária da pousada de 27 anos de idade disse: “É importante nossa cidade ser documentada de patrimônio, mas importante mesmo é isso não mudar muito nossa vida". Além desse relato, outros também comentaram ter receio de que a cidade fique muito conhecida pois pretendem manter seus ritmos de vida, tradições e identidades locais", o que tem ficado cada vez mais difícil em um mundo conectado por redes.

Appadurai (1994, p. 324) pontua que "o aspecto central da cultura global atual é a política do esforço mútuo da igualdade e da diferença". E ainda que a globalização da cultura não é o mesmo que sua homogeneidade. Ou seja, apesar da globalização envolver o uso de uma variedade de instrumentos de homogeneização, esses são absorvidos na economia política e cultura local, para serem repatriados somente com diálogos heterogêneos. Isso nos leva a compreensão que, por mais que a cidade de Goiás esteja, de certa maneira, inserida nos meios de comunicação, na rede de transportes e receba de várias maneiras as influências do mundo global, as vezes materializadas pela presença de visitantes que convivem na cidade, esses encontros não significam necessariamente a formação de um todo homogêneo.

\footnotetext{
2 SIC: "assim", "desta forma", "assim estava escrito". Nota metodológica explicativa: todos os diálogos realizados em trabalho de campo foram transcritos da forma como foram coletados, o objetivo foi registrar os modos de fala dos sujeitos entrevistados.
} 
SENA, C. C. A.

Cidade histórica turística, globalização e identidades: conflitos e rearranjos na Cidade de Goiás (GO) observados na alimentação

\section{VIDA ESTUDANTIL E A QUESTÃO DAS IDENTIDADES NA CIDADE DE GOIÁS}

$\mathrm{Na}$ Cidade de Goiás a presença de instituições de ensino superior trouxe um elemento importante no conflito entre identidade local-global. Nessa seção o destaque está para o público atendido tanto pela Universidade Federal de Goiás (UFG) quanto a Universidade Estadual de Goiás (UEG), além do Instituto Federal de Goiás (IFG), sobretudo os estudantes, que tendem a se mudar para essa cidade a fim de concluírem seus cursos.

O convívio dos estudantes com moradores desta cidade é, certamente, mais intenso do que o convívio dos turistas, pois os estudantes passaram a ser também habitantes do lugar, e aos poucos, se sentem inclusos e pertencentes da dinâmica urbana. O fato de parte considerável dos estudantes entrevistados para a pesquisa não terem nascido na Cidade de Goiás, ou nem mesmo no estado, possuem hábitos e formas de interagir com o centro histórico bem diferenciados.

Um estudante do curso de Direito da Universidade Federal de Goiás comentou: "quando eu mudei pra cá, tive que alugar um lugar e vi que as pessoas não gostavam muito dos estudantes, depois foi melhorando, a gente foi acostumando com eles e eles com a gente" (sic). G.A.Z.O.A, 25 anos. Ele contou ainda ter percebido melhoria significativa no convívio entre estudantes e moradores ao longo dos anos que passou na universidade, na data do trabalho de campo já tinham se passado 4 anos de convivência. Ao exemplificar essas melhorias, o estudante lembrou a oferta de hospedagem e o aumento no número de estabelecimentos comerciais. Por outro lado, o que o estudante alega ser uma melhoria de infraestruturas, nem sempre é visto como um avanço para a população local.

Ainda de acordo com o estudante, um dos bares da Cidade de Goiás mais frequentados por estudantes se chama "Morro do Macaco Molhado". Esse bar atende seus clientes diferentemente a depender de serem turistas ou residentes. Além do atendimento formal, existe a possibilidade de abrir o bar em horários inusitados, o que nem todo mundo sabe:

O bar é meio escondido, muito turista nem sabe que ele existe. Além disso, eu só aprendi com o tempo que quando está fechado, não necessariamente está fechado. Quando entrosei na cidade, descobri que a gente pode bater na janela do dono e ele abre o bar em horários estranhos, mas isso depende de certa intimidade, é claro. (G.A.Z.O.A, estudante). 
SENA, C. C. A.

Cidade histórica turística, globalização e identidades: conflitos e rearranjos na Cidade de Goiás (GO) observados na alimentação

Seja pela presença da universidade seja pela presença dos turistas, aumentaram a frequência de visitas à cidade Goiás desde quando passou a ser "cidade patrimônio". A diversidade cultural que passou a adentrar o território, contribui para a construção de várias identidades dentro de uma mesma cidade, bem como da ressignificação das já existentes. Da mesma forma que o estudante migrante precisa secundarizar alguns traços de sua cultura para se inserir em Goiás, a chegada de hábitos e modos de vida diferentes dos da população local, também causam um impacto na população local.

O estudante de Direito relatou na mesma entrevista um exemplo em que a população local - por meio dos funcionários do serviço de segurança pública, precisou refletir melhor a presença dos novos moradores, objetivando evitar atos de violências desnecessária: "um amigo chegou a apanhar da polícia porque estava fumando um cigarro de palha, o policial pensou que era maconha. Nesse caso tivemos que conversar, a universidade fez intervenções pontuais e no fim deu certo" relatou G.A.Z.O.A.

Os diálogos analisados revelam a busca por conforto quando sujeitos parecem querer equilíbrio entre manter suas identidades ao relacionar com as identidades dos (as) outros (as). Encontrar um meio termo é difícil, pois a linha entre manter tradições ou interagir com a cultura global é tênue. Essa realidade é sintetizada por Bauman (2006) ao discorrer sobre a procura incessante dos humanos de uma imagem de harmonia, lógica e consistência na experiência humana. Bauman ainda reforça que identidade é segurança estabelecida pelos indivíduos e grupos em seus territórios políticos administrativos constituídos durante a modernidade.

\section{ALIMENTAÇÃO E TERRITÓRIO: O QUE OS ESTABELECIMENTOS VILABOENSES PODEM REVELAR}

Neste tópico do artigo, pretende-se analisar algumas paisagens da cidade de Goiás

por meio da leitura de algumas fotografias retiradas em trabalho de campo. É verificado também a evolução do número de estabelecimentos alimentícios e imobiliários que atendem turistas e estudantes, com a finalidade de exemplificar com dados e o empirismo do trabalho de campo o que tem sido discutido também teoricamente. Ainda antes das considerações 
SENA, C. C. A.

Cidade histórica turística, globalização e identidades: conflitos e rearranjos na Cidade de Goiás (GO) observados na alimentação

finais foi feita uma interpretação de um cardápio de um restaurante local apontado por moradores como um bom restaurante e que representa a culinária goiana.

A Tabela 1 apresenta as subclasses de Classificação Nacional de Atividades Econômicas - CNAE, que organiza os estabelecimentos produtivos do país em diversos setores. Nessa tabela foram compiladas três categorias ligadas à alimentação nos anos de 2002 até 2014. O primeiro ano da base de dados exibida é um ano após o tombamento da Cidade de Goiás como patrimônio mundial pela UNESCO, que ocorreu em 2001, desde então foi observado depois de 4 anos, uma aceleração na quantidade de estabelecimentos.

Tabela 1 - Número de estabelecimentos vinculados à alimentação na cidade de Goiás (2002-

2014)

\begin{tabular}{c|c|c|c}
\hline Ano & Alimentação & $\begin{array}{c}\text { Fabricação de Produtos } \\
\text { Alimentícios }\end{array}$ & Fabricação de Bebidas \\
\hline 2014 & 25 & 3 & 1 \\
\hline 2013 & 24 & 4 & 2 \\
\hline 2012 & 23 & 3 & 2 \\
\hline 2011 & 18 & 5 & 2 \\
\hline 2010 & 24 & 5 & 1 \\
\hline 2009 & 20 & 9 & 1 \\
\hline 2008 & 20 & 7 & 1 \\
\hline 2007 & 20 & 7 & 0 \\
\hline 2006 & 22 & 6 & 0 \\
\hline 2005 & 0 & 0 & 0 \\
\hline 2004 & 0 & 0 & 0 \\
\hline 2003 & 0 & 0 & 13 \\
\hline 2002 & 0 & 0 & \\
\hline Total & 196 & 49 & \\
\hline
\end{tabular}

Fonte: CNAE 2.0 | RAIS (2017). Organização: O Autor (2017).

De acordo com a plataforma RAIS (2017), até 2005 os estabelecimentos ligados ao setor de alimentação eram inexistentes. Tal realidade começou a mudar no ano de 2006 e nos últimos anos se intensificando. Vários fatores explicam esse aumento, um deles foi a instalação dos estabelecimentos de educação superior, já relatados nesse texto. Uma das formas de se entender a crescente construção dos estabelecimentos apresentados, pode ter relação com a chegada da Universidade Federal da Cidade de Goiás, no ano de 2009, o do Instituto Federal, em 2012. Antes disso, ocorreu a unificação da Universidade Estadual de Goiás à rede da UEG, em 1999. 
SENA, C. C. A.

Cidade histórica turística, globalização e identidades: conflitos e rearranjos na Cidade de Goiás (GO) observados na alimentação

A crescente oferta de cursos tem atraído a atenção de estudantes e pode explicar o número de 19 estabelecimentos novos disponíveis para aluguéis na última coluna da tabela 1 . Nota-se, portanto, ainda segundo a tabela 1, que os estabelecimentos de alimentação, fabricação de produtos alimentícios e fabricação de bebidas, a partir de 2014 já somam 258 estabelecimentos, o que altera significativamente a disponibilidade de alimentos para a população. Até 2015 a cidade de Goiás já havia realizado 9 edições de um festival gastronômico, um atrativo turístico que aos poucos começa a fazer parte da agenda cultural da cidade.

A partir da possível importância deste festival, questiona-se: o aumento de estabelecimentos e a criação de um festival gastronômico, representam de alguma forma um traço da identidade da cidade de Goiás? Aparentemente, esses elementos causam contraste e vão, aos poucos, ressignificando o território e as paisagens da cidade histórica, a transição de identidade parece ser um processo mais lento.

Com objetivo de apresentar diante das paisagens da cidade de Goiás, como esses novos estabelecimentos são inseridos na paisagem, apresenta-se duas figuras de estabelecimentos alimentícios totalmente divergentes: a Figura 2 com uma casa de doces e sua fachada no estilo cidade histórica goiana, com um cuidado inclusive de pensar na tipografia e na preservação de uma coloração específica para as paredes e o estilo da janela, ao lado da Figura 3, uma distribuidora de bebidas, com cores vermelhas destoando de todas as outras fachadas tombadas como patrimônio histórico pelo Iphan ou Unesco.

Figura 2 - Casa de doces cristalizados (esquerda).

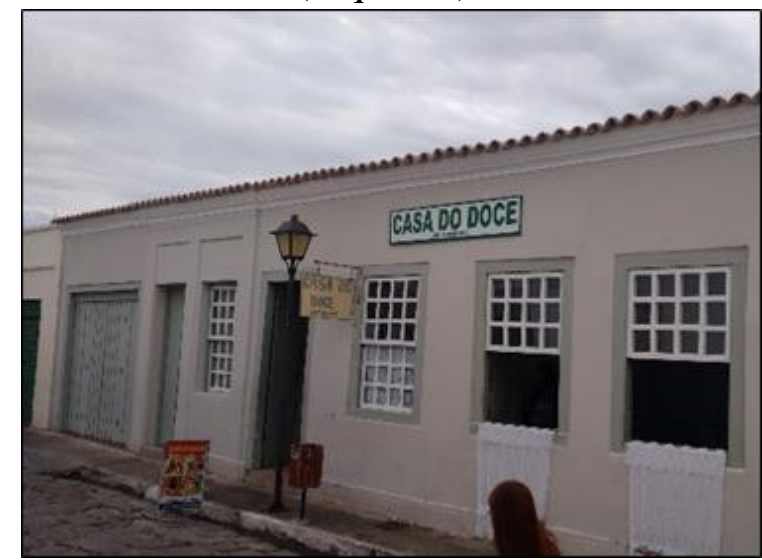

Figura 3. Distribuidora de Bebidas - Cidade de Goiás (direita).

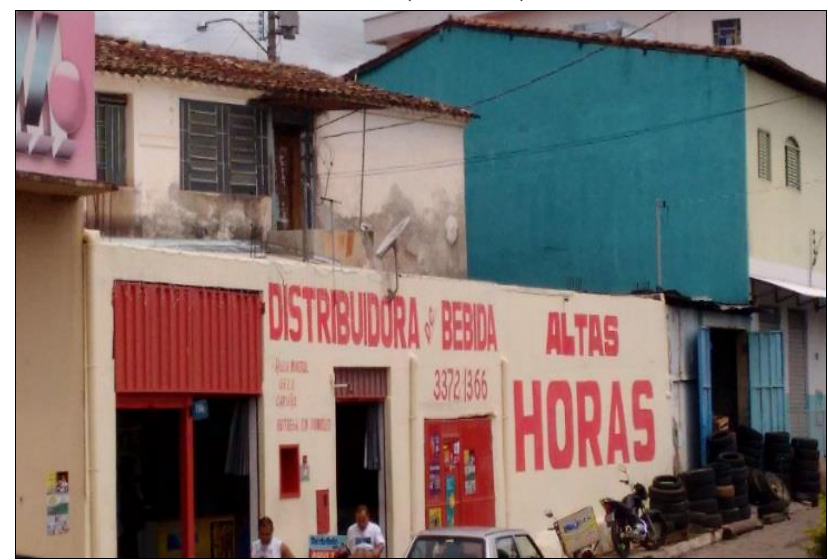

Fonte: Trabalho de campo. Foto: O autor (2015). 
SENA, C. C. A.

Cidade histórica turística, globalização e identidades: conflitos e rearranjos na Cidade de Goiás (GO) observados na alimentação

O nome da distribuidora de bebidas é inclusive de um programa da televisão aberta. Os dois estabelecimentos são frequentados tanto por turistas, estudantes ou moradores locais. Apesar disso, a relação que os mesmos promovem na paisagem ou nos hábitos da cidade é bem diferente e será analisado na sequência.

Nas ruas da cidade de Goiás, é possível observar com alguns metros de diferença, na área tombada (figura 2) ou nas zonas menos centrais (figura 3), dois estabelecimentos de alimentação e bebidas. O primeiro deles, remonta o simbolismo dos doces cristalizados com a sociedade vilaboense, os doces fazem parte inclusive de alguns dos personagens mais emergentes na história da cidade. O segundo estabelecimento (Figura 3), além de abandonar o padrão arquitetônico tradicional de cidade histórica, como dito anteriormente, chama atenção o termo "altas horas", cuja demanda de serviços funcionando até parte da madrugada, relaciona-se de forma mais próxima com turista e o estudante com morada temporária do que com quem já está na cidade há décadas. Pois foram relatados em entrevistas do trabalho de campo que parte dos idosos da cidade costuma dormir mais cedo.

Porém, apesar de significar uma notória ruptura com os hábitos locais, tanto a casa de doces quanto o estabelecimento que vende bebidas até mais tarde convivem em uma mesma mancha urbana. Observou-se em campo que os moradores mais antigos as vezes reclamam com os jovens sobre novas construções que mudam o ritmo da cidade, e utilizam como argumento que os órgãos de preservação e tombamento arquitetônico e promoção do turismo devem continuar cuidado do centro histórico para que a cidade não perca verbas importantes para a manutenção do patrimônio e, em outro plano, o "status" de cidade histórica tombada.

Por outro lado, com a intensificação de fluxos populacionais e posturas diversas dentro da cidade de Goiás, outros elementos podem ganhar força e, em um futuro, o que atualmente é entendido como relevante à identidade da cidade de Goiás, pode ser alterado, seja para incorporar novos elementos sou para abrir mão do que a população passa a não se identificar mais. A identidade apresenta uma variabilidade elevada em termos tanto temporais quanto espaciais; tal variabilidade era maior na dimensão temporal do que na espacial (POLLICE, 2010, p. 355). Outra leitura que se faz sobre identidade e contemporaneidade, com base nas problemáticas apresentadas sobre tradição e elementos da globalização é a própria crise de identidade, bastante marcada no discurso de Hall (1997). Esse autor assinala 
SENA, C. C. A.

Cidade histórica turística, globalização e identidades: conflitos e rearranjos na Cidade de Goiás (GO) observados na alimentação

que o sujeito contemporâneo está vivendo uma crise de identidade, relacionando isso ao processo de globalização, com o maior fluxo de informações e transporte, os elementos da cultura global pasteurizados correm o risco de se sobrepor aos elementos da cultura local.

Algo perceptível nos estabelecimentos de alimentação na cidade de Goiás que demonstra essa crise alertada por Hall, é o comércio atual da culinária na cidade história. Seja nas comidas de rua, restaurantes ou pequenos comércios, existe uma mistura de tradição em diálogo com o contemporâneo industrial constante, com elementos que até então pouco faziam parte da cidade de Goiás. Esses elementos novos ganham força, pois existe um maior diálogo dos jovens com o que é de fora, em um processo sedutor pautado na pluralidade, que criam demandas, desejos e anseios, principalmente no comportamento da população mais jovem e estudantes, é comum o tradicional colidir com o global e industrial.

Figura 4 - Coca-Cola, Skol e Antarctica na porta da casa de Cora Coralina

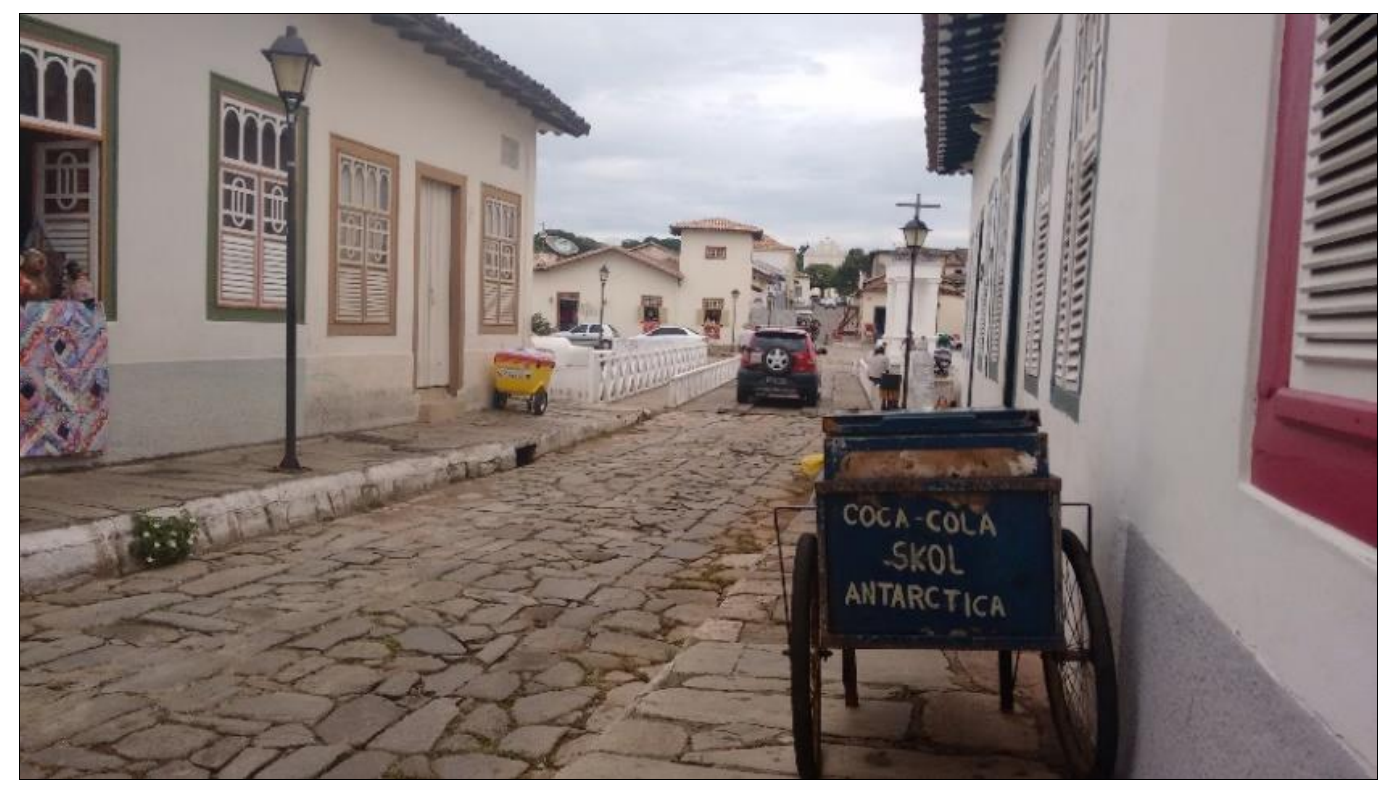

Fonte: Trabalho de campo. Foto: O autor (2015).

Na Figura 4, pode-se observar empiricamente, o refletido por Hall (1997), pois elementos da cultura tradicional da cidade de Goiás, como os doces cristalizados e o Museu da Cora Coralina, convivem no mesmo espaço que os elementos globais, como é o caso do refrigerante Coca-Cola. Ou seja, elementos locais e globais convivem no centro histórico da cidade, não parece ser possível frear as interferências da cultura global na cultura popular. Esses elementos não revelam uma crise em si de identidade, mas podem significar minimante 
SENA, C. C. A.

Cidade histórica turística, globalização e identidades: conflitos e rearranjos na Cidade de Goiás (GO) observados na alimentação

um maior convívio de diferentes referências em um mesmo território, que pode, no futuro, colocar em choque o padrão de "tradição" ou de "identidade" vilaboense.

Ainda de acordo com Hall (1997), o caminho para evitar uma possível crise de identidade não parece ser a tentativa de isolar ou diminuir tal interferência do global ou do industrial no artesanal da cidade de Goiás. Pois o mundo possui lógicas diversas que se somam e assim se complementam. É o caso de se pensar que a identidade proporcionada pelos estabelecimentos de alimentação em Goiás tem ganhado novos elementos e formas de se exibir: tanto arquitetonicamente quanto no conteúdo que é comercializado. A repressão desses estabelecimentos que destoam do padrão pode não fortalecer a cultura vilaboense, pois os novos moradores e a parcela mais jovem da população têm demonstrado interesse em incorporar e frequentar esses estabelecimentos.

As marcas dos novos estabelecimentos e desse convívio entre tradicional e contemporâneo não se restringe na alteração das fachadas da cidade por meio das figuras 2, 3 e 4 aqui apresentadas. Essas modificações encontram respaldo em mudanças também dentro dos lares e nas formas de viver da população da cidade de Goiás. Tomando como referência os estabelecimentos que vendem alimentos, além da fachada e do tipo de público, acontece mudança dentro dos restaurantes e ampliação do diálogo entre o local e o global também nos ditos lugares mais tradicionais ou antigos. Como exemplo pode-se apresentar as mudanças no próprio cardápio, que diz muito sobre o tipo de consumo e oferta de alimentos.

Nas Figuras 5 e 6 podem ser observados os pratos comercializados pelo Restaurante Dali Sabor \& Arte. Ele é um estabelecimento central na cidade de Goiás, localizado às margens do Rio Vermelho, e é possível verificar, por meio da alimentação, a apropriação da culinária e cultura mundial, convivendo com pratos típicos e tradicionais goianos.

Nesse cardápio, o tradicional Empadão goiano e Arroz com pequi (figura 6) dividem espaço com o Yakissoba japonês, a panqueca norte americana em uma adaptação que mistura a massa original com o recheio goiano de frango com milho (figura 5). Sem contar com a venda, na primeira linha do cardápio, da Lasanha Tradicional, que juntamente com o spaghetti seriam pratos italianos. Esses exemplos comprovam o que Claval (1999, p. 255) chama de "terreno fértil para análises geográfica". Ele ressalta a relevância dos alimentos para 
SENA, C. C. A.

Cidade histórica turística, globalização e identidades: conflitos e rearranjos na Cidade de Goiás (GO) observados na alimentação

os estudos ao destacar processos relacionados a vivência do ser humano com a busca por comida, como no trecho: "Alimentar-se, beber e comer: não há terreno de análise mais fascinante para os geógrafos. As relações ecológicas dos homens com seu ambiente exprimem-se diretamente nos consumos alimentares".

Figura 5 e 6: Cardápio do Restaurante Dali: Yakissoba, Panqueca ou Empadão goiano?
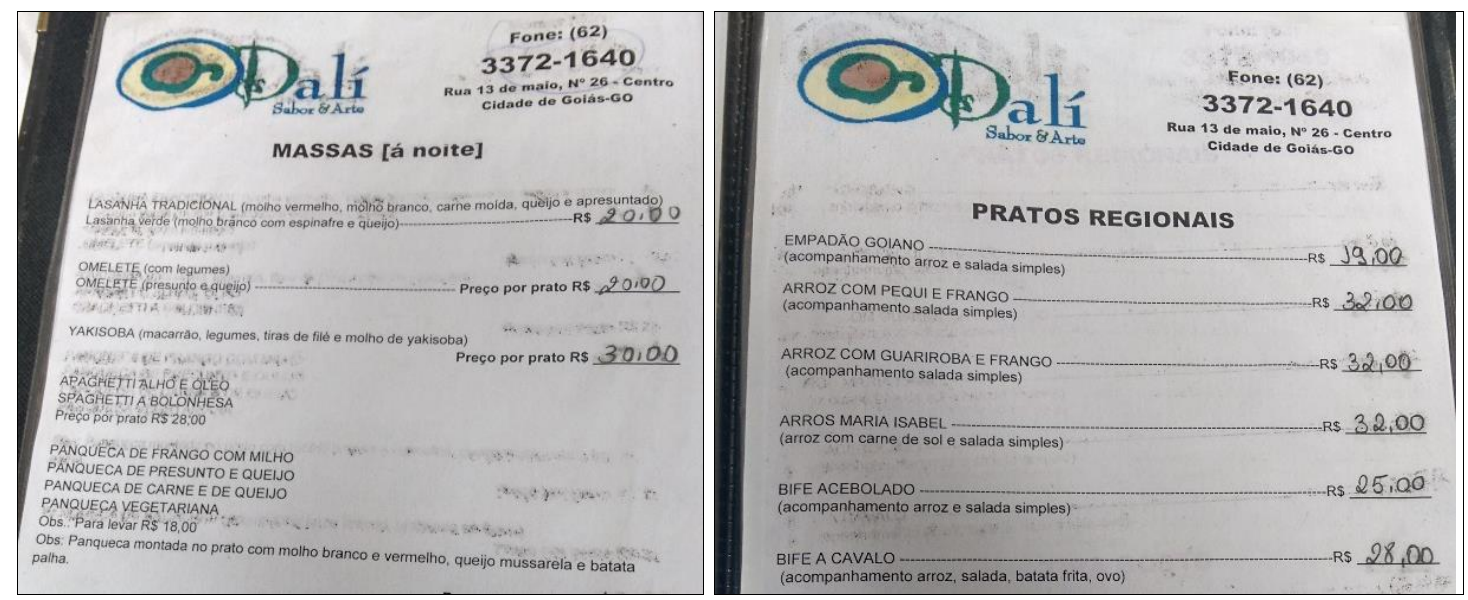

Fonte: Trabalho de campo. Foto: O autor (2015).

A respeito da relação da comida, identidade e organização social, Garcia (1994, p. 01) sinaliza que nas práticas alimentares "[...] a subjetividade veiculada inclui a identidade cultural, a condição social, a religião, a memória familiar, a época, que perpassam por esta experiência diária". A aparente apresentação dos pratos nos cardápios, a instalação de estabelecimentos de ensino superior ou ainda a criação de novos estabelecimentos de alimentação, podem incorporar informações sobre as dinâmicas territoriais, culturais e sociais - o que mais tarde pode significar também alterações ou ressignificações na identidade local.

\section{CONSIDERAÇÕES FINAIS}

Este artigo apresentou a possibilidade de se compreender o território a partir da alimentação, entendendo-a como traço da cultura na cidade de Goiás. O estudo buscou apresentar um olhar crítico em relação às construções de identidades em territórios turísticos tombados como patrimônio histórico e cultural da humanidade. Foi compreendido que as construções de identidades são plurais e estão em constante movimento e ressignificação. 
SENA, C. C. A.

Cidade histórica turística, globalização e identidades: conflitos e rearranjos na Cidade de Goiás (GO) observados na alimentação

Notou-se ainda que nem sempre a discussão sobre as identidades precisa caminhar junto com uma possível tentativa de "representação" de pessoas, territórios ou lugares ou, além disso, nem sempre é possível selecionar algum elemento que se coloque como possibilidade única ou dominante em uma cultura tão plural tanto do passado como do presente ou futuro. Muitas identidades também são constituídas de forma vertical por poderes hegemônicos, e trazem consigo uma série de contradições.

Apesar disso, existe uma força evidente no poder estratégico das identidades (sejam elas forjadas ou autênticas) na sociedade contemporânea e com repercussão nas ações dos territórios junto à gestão pública e privada de recursos. Na cidade de Goiás, a intensificação do fluxo de pessoas ocorreu primeiramente após o tombamento como cidade patrimônio e, depois, por conta da instalação de universidades e um instituto federal - que atraiu o público jovem, que por sua vez criou demandas que incentivaram o aumento do número de estabelecimentos alimentícios na cidade histórica. Verificou-se a partir de algumas entrevistas e de novas territorialidades que os hábitos alimentares nas cidades históricas têm mudado com o passar do tempo. Essa mudança tem repercutido nos cardápios e nos lugares dedicados às refeições: fora e dentro de casa. Dessa forma, estima-se que a construção do que pode ser considerada comida típica ou comidas que representem as identidades da cidade de Goiás, pode sofrer alterações em um futuro próximo.

Esse artigo dedicou atenção especial aos estabelecimentos de alimentação, ao analisar as características que os mesmos podem revelar no território, no modo de vida das pessoas e, principalmente, no diálogo entre as identidades local-global verificados por meio da disponibilidade de pratos no cardápio de um restaurante central e na fachada dos comércios.

A análise de territórios em regiões turísticas pode favorecer o processo dialógico que são as construções identitárias ou pode deixar a pluralidade que é o debate das mesmas. Nos territórios apropriados por atividades do turismo, convivem cotidianamente sujeitos que não necessariamente possuem identificações ou construção histórica de vínculo com as identidades locais, sendo pessoas capazes de trazer novidades de outros territórios e também de trazer referências que causam conflitos e choques aos costumes pré-estabelecidos.

A partir da convivência entre novos e antigos moradores ou da visita de turistas, pode-se gerar conflitos de gerações e de identidades. Esse diálogo nem sempre brando, pode 
SENA, C. C. A.

Cidade histórica turística, globalização e identidades: conflitos e rearranjos na Cidade de Goiás (GO) observados na alimentação

causar reflexões e reordenamentos nos eixos culturais e simbólicos de cidades históricas, pois os elementos impactantes industriais e/ou advindos de outros territórios com as facilitações de fluxos propostas pela globalização causa certo impacto no que é tido como tradicional ou "tombado". Esse choque de identidades e a recepção de símbolos globais nas cidades históricas, tanto podem enriquecer a cultura local, que passa a se autoquestionar e fortalecer seus símbolos, quanto podem ocasionar um deslocamento das tradições, histórias, memórias e, por fim, das identidades a partir de um processo dialógico entre a tradição e o mundo contemporâneo em redes. Esses elementos são interessantes ao estudo geográfico.

\section{AGRADECIMENTOS}

Ao Conselho Nacional de Desenvolvimento Científico e Tecnológico (CNPq) pela concessão da bolsa de pesquisa durante o mestrado.

\section{REFERÊNCIAS}

ALMEIDA, M. G. de. Geografia Cultural: Contemporaneidade e uma flashback na sua ascensão no Brasil. In: MENDOÇA, F. A. et. al. (Org.) Espaço e Tempo: complexidade e desafios do pensar e do fazer geográfico. Curitiba: Associação de Defesa do Meio Ambiente e Desenvolvimento de Antoina (ADEMADAN), 2009. p. 243-260.

AMIN, S. Mundialização, crise e transição. In: Revista Novos Rumos, n. 30, p. 7 -12, 1999. Disponível em:

http://www2.marilia.unesp.br/revistas/index.php/novosrumos/article/view/1914. Acesso em Fev de 2017.

APPADURAI, A. Disjunção e Diferença da Economia Cultural e Global. In:

FEATHERSTONE, M. (Org.). Cultural Global: nacionalismo, globalização e modernidade. Petrópolis: Vozes, 1994. p. 311-327.

BAUMAN, Z. Modernidade Liquida. Tradução Fondo de Cultura Económica. Buenos Aires, 2006. p. 99-138

CANCLINI, N. G. No sabemos cómo llamar los otros. In: CANCLINI, N. G. La globalización imaginada. México: Paidós, 2001.

CASTELLS, M. A sociedade em rede. Tradução de Roneide Venâncio Majer. São Paulo: Paz e Terra, 1999.

CLAVAL, P. A Geografia Cultural. Florianópolis: UFSC, 1999, 453p 
SENA, C. C. A.

Cidade histórica turística, globalização e identidades: conflitos e rearranjos na Cidade de Goiás (GO) observados na alimentação

CLAVAL, P. La geografía en recomposición: objetos que cambian, giros múltiples. ¿Disolución o profundización? In: LINDÓN, A; HIERNAUX, D. (Orgs.) Los Giros de la Geografia Humana: Desafíos y horizontes. México: Anthropos, 2010. p, 63-82.

CRUZ, V. C. Itinerários teóricos sobre a relação entre território e identidade. In: BEZERRA, A. C.A. et. Al. (Orgs). Itinerários Geográficos. Niterói. EdUFF, 2007. p,13-35.

FOUCAULT, M. Microfísica do poder. 4ª ed., Rio de Janeiro: Graal, 1984.

FOUCAULT, M. A ordem do discurso. São Paulo: Ed. Loyola, 1996.

GARCIA, R. W. D. Representações Sociais da Comida no Meio Urbano: algumas considerações para o estudo dos aspectos simbólicos da alimentação. In: Revista Cadernos de Debate. Vol. II. São Paulo, 1994.

GOMES, P. C. da C. Sobre Territórios, Escalas e Responsabilidade. In: HEIDRICH, A. L. et.al. (Orgs). A Emergência Multiterritorialidade: A ressignificação da relação do humano com o espaço. Porto Alegre: Editora da UFRGS, 2005. p, 37-45.

HOBSBAWM, E; RANGER, T. (orgs.). A invenção das tradições. Rio de Janeiro: Paz e Terra, 1984.

HALL, S. A identidade Cultural na Pós-Modernidade. Tradução: Tomaz Tadeu da Silva Guacira Lopes Lobo. Rio de Janeiro: DP\&A, 1997.

HAESBAERT, R. Des-territorialização e identidade: a rede "gaúcha" no Nordeste. RJ: EDUFF, 1997.

HAESBAERT, R. Dilemas de Conceitos: Espaço-território e Contenção Territorial. In: SAQUET, M. A; SPOSITO, E. S. (Orgs.). Territórios e Territorialidades: Teorias, Processos e Conflitos. São Paulo: Expressão Popular, 2009. p. 95-120.

HAESBAERT, R. Globalização e fragmentação no mundo contemporâneo. Niterói: EdUff, 1998.

NORA, P. Entre memórias e história: a problemática dos lugares. Projeto História, São Paulo, n. 10, p. 7-28, 1993.

ORTIZ, R. Mundialização e cultura. São Paulo: Brasiliense, 1994.

PALACÍN, L. O século do ouro em Goiás. Goiânia: UCG, 1994.

PAES, M.T.D. As cidades coloniais brasileiras: Ideologias espaciais, valores histórico, urbanístico e cultural. GEOgraphia (UFF), v. 15, p. 41-68-68, 2015.

POLLICE, F. O papel da identidade territorial no desenvolvimento local. Espaço e Cultura, UERJ, RJ, n. 27, p. 7-23, jan-jun, 2010. 
SENA, C. C. A.

Cidade histórica turística, globalização e identidades: conflitos e rearranjos na Cidade de Goiás (GO) observados na alimentação

SANTOS, M. Território e dinheiro. In: Revista GEOgraphia. Niterói: programa de PósGraduação em Geografia - PPGEO - UFF/AGB, v.1, n1. p. 7 a 13, 1999.

SANTOS, M. Por uma outra globalização - do pensamento único à consciência universal. Rio de Janeiro: Record, 2000.

SAQUET, M. A. A Abordagem Territorial: considerações sobre a dialética do pensamento e do território. In: HEIDRICH, A. L. et al (Orgs). A emergência da Multiterritorialidade: a ressignificação da relação do humano com o espaço. Porto Alegre: Editora da UFRGS, 2005 p. 47-60.

SILVA, A. S. Identidades sociais: continuidade e mudança. In: Dinâmicas multiculturais, novas faces, outros olhares. Vol. 1. Lisboa: Instituto de Ciências Sociais da Universidade de Lisboa, 1996, p. 31-36.

SEBRAE Goiás (2015). Elementos da iconografia de Goiás. Disponível em: < https://goo.gl/rbG3gD>. Acesso em: 01 fev. 2016.

\section{Autor}

Caio César Alencar de Sena - Graduado em Geografia pela Universidade Federal de Goiás (UFG) com um ano de intercâmbio na Katholische Universität de Eichstätt-Ingolstadt (KUEI), na Alemanha. É Mestre e atualmente cursa Doutorado pelo Programa de PósGraduação em Geografia do Instituto de Estudos Socioambientais (IESA/UFG).

Artigo recebido em: 13 de novembro de 2018.

Artigo aceito em: 18 de dezembro de 2018.

Artigo publicado em: 21 de dezembro de 2018. 